\title{
Impact of the Healthy Foods North nutrition intervention program on Inuit and Inuvialuit food consumption and preparation methods in Canadian Arctic communities
}

\author{
Fariba Kolahdooz ${ }^{1}$, Mohammadreza Pakseresht ${ }^{1}$, Erin Mead ${ }^{2}$, Lindsay Beck' ${ }^{1}$, André Corriveau ${ }^{3}$ \\ and Sangita Sharma ${ }^{*}$
}

\begin{abstract}
Background: The 12-month Healthy Foods North intervention program was developed to improve diet among Inuit and Inuvialuit living in Arctic Canada and assess the impact of the intervention established for the communities.

Methods: A quasi-experimental study randomly selected men and women ( $\geq 19$ years of age) in six remote communities in Nunavut and the Northwest Territories. Validated quantitative food frequency and adult impact questionnaires were used. Four communities received the intervention and two communities served as delayed intervention controls. Pre- and post-intervention changes in frequency of/total intake of de-promoted food groups and healthiness of cooking methods were determined. The impact of the intervention was assessed using analysis of covariance (ANCOVA).

Results: Post-intervention data were analysed in the intervention $(n=221)$ and control $(n=111)$ communities, with participant retention rates of $91 \%$ for Nunavut and $83 \%$ for the Northwest Territories. There was a significant decrease in de-promoted foods, such as high fat meats $(-27.9 \mathrm{~g})$ and high fat dairy products $(-19.8 \mathrm{~g})$ among intervention communities (all $p \leq 0.05$ ). The use of healthier preparation methods significantly increased (14.7\%) in intervention communities relative to control communities.
\end{abstract}

Conclusions: This study highlights the importance of using a community-based, multi-institutional nutrition intervention program to decrease the consumption of unhealthy foods and the use of unhealthy food preparation methods.

Keywords: Healthy Foods North, Inuit, Inuvialuit, Food consumption, Food preparation, Arctic, Dietary intervention

\section{Background}

Approximately 30\% of Inuit and 35\% of Inuvialuit over the age of 15 years reported having at least one chronic health condition in 2008 [1]. Additionally, about $57 \%$ of the population residing in the Northwest Territories is overweight or obese, compared to $54 \%$ of the national Canadian average [2]. Overall, Indigenous people in Canada have a life expectancy 8 to 13 years lower than non-Indigenous Canadians $[3,4]$, which may contribute to this populations'

\footnotetext{
* Correspondence: gita.sharma@ualberta.ca

'Aboriginal and Global Health Research Group, Department of Medicine, Faculty of Medicine and Dentistry, University of Alberta, Unit 5-10, University Terrace, 8303-112 Street, Edmonton, AB T6G 2T4, Canada

Full list of author information is available at the end of the article
}

relatively high health care costs (approximately 1.8-2.2 times the Canadian average) [5].

The lifestyle and diet changes experienced by Indigenous peoples during the last decades influence diet quality, which affects the prevalence of nutrition-related chronic diseases (e.g. hypertension, diabetes, obesity, and some forms of cancer) in Canadian Indigenous populations residing in Nunavut (NU) and the Northwest Territories (NWT) [6-10]. Several studies of Inuit and Inuvialuit populations have documented rapid socio-economic and cultural transitions related to acculturation which have ultimately led to a shift away from traditional diets and procurement practices towards increased dependence on non-nutrient-dense, store-bought foods [10-13]. Populations residing in NU and the NWT are further challenged 
by their remote location [13] and the increasing cost of food [14], creating reliance on inexpensive non-perishable processed foods that are usually non-nutrient-dense [15].

Recent assessments in Inuit and Inuvialuit adults found that dietary fiber, calcium, folate, and vitamins $\mathrm{A}$ and $\mathrm{E}$ (and vitamin D among women) were below the recommendations in $60-100 \%$ of participants [16,17]. In addition, recent studies found a high prevalence of preparation methods that add fat to foods (e.g. frying with lard) [18,19]; these preparation methods are determinants of fat intake $[20,21]$ and risk factors for impaired glucose tolerance [22] among Inuit and Inuvialuit populations.

Health promotion programs that concentrate on healthy eating for the reduction of chronic disease should use a comprehensive approach that combines individual, organizational and policy levels in order to effectively address the multilevel risk factors [6]. Furthermore, store-based environmental interventions that integrate behavior change strategies have proven effective in improving diet with other Indigenous and low-income populations [23-25]. Combined environmental and behavioral approaches have been shown to be one of the most promising ways to improve diet and reduce risk of chronic disease [26].

Healthy Foods North (HFN) was an evidence-based intervention program designed specifically for Inuit and Inuvialuit populations to reduce the risk of chronic disease by improving diet and increasing physical activity. HFN combined behavioral and environmental strategies through community-based activities, multi-institutional partnerships, and point of purchase to increase the availability, accessibility and visibility of healthy foods as well as opportunities for physical activity. HFN was tailored to build on the strengths and meet the specific needs of the communities through culturally appropriate programming [24,27-29]. Key elements of HFN included the promotion of healthier food preparation methods, the multitude of benefits related to traditional foods, and healthier options in stores $[13,28]$. These traditions included food sharing, survival from the land and respect for food [30].

The purpose of this study was to evaluate the 12 month HFN intervention program by: 1) determining pre- to postintervention changes in grams/day and frequency of consumption of de-promoted (i.e., discouraged) food groups, such as store-bought high-fat meats and unhealthy drinks; and 2) comparing pre- and post-intervention changes in healthy and unhealthy preparation methods.

\section{Materials and methods}

\section{Setting}

This study was a quasi-experimental intervention evaluation conducted in the Kitikmeot region in NU and the Beaufort Delta region in the NWT. Two remote communities in NU along with one semi-remote and one remote community in the NWT received the HFN intervention program. Two additional remote communities (one each in NU and the NWT) served as comparison controls, receiving a delayed intervention following the completion of post-intervention data collection. These communities have previously been described in detail [13]. Communities were selected for participation because of their varying proportions of Inuit or Inuvialuit populations, socioeconomic status, degree of acculturation, and degree of traditional food access 13]. The three NU communities ranged in size from $800-1,500$ people, $80-90 \%$ of whom selfidentify as Inuit. The median Inuit age ranged from 20-26 years, and the employment rate ranged from $40-60 \%$. The three communities in the NWT ranged from 400-3,500 people, with Inuvialuit populations ranging from 40-90\% of the community. The median age of Inuvialuit in these communities ranged from $24-26$ years, and $40-65 \%$ were employed [31]. Each of the six communities had 2-3 food stores that obtain food primarily via airplane year round, roads and/or ice roads for part of the year, and barge or sea lift once per year when the sea ice melts. Food is also obtained, to varying degrees, by traditional means (e.g. hunting, fishing, food sharing networks).

\section{Sampling}

Households were recruited by random selection using upto-date community housing maps provided by the local governments. One resident per household, ideally the person who was the main food shopper/preparer, was recruited. Exclusion criteria included pregnant and lactating women (due to this groups' different nutritional requirements and possible changes in dietary habits) and residents $<19$ years. Assignment of communities to the intervention or control group was decided by the government and was based on population size, the percentage of Inuit or Inuvialuit in the population, wage economy and engagement in traditional food gathering practices [32].

\section{Intervention development and implementation}

Community participatory research [24] was used to identify the themes of the interventions and have previously been described in detail [13]. The intervention program included five phases and each focused on promoting certain healthy food options and approaches to physical activity. The first phase entailed six months of informative research to understand local conceptions of healthy foods and cultural norms around food practices. In the second phase, In-depth interviews with community stakeholders and community workshops were conducted through two two-day workshops to develop the intervention $[19,24]$. The interviews and workshops sought information on important dietary practices and behaviors valued by Inuit and Inuvialuit community members. In the third phase, the evidence was reviewed and these results were integrated into culturally-appropriate, relevant, and attainable 
intervention components and materials. The fourth phase involved 3-day training for intervention trainees, local community health representatives, project coordinators, and local store staff and the fifth phase was the actual program implementation and evaluation. Elders and community members emphasized the importance of 'country' foods (foods from the land, air, or sea such as caribou, seal, fish, ptarmigan, goose, or berries); as such, many of the intervention materials focused on ways to prepare traditional foods. Traditional procurement practices, such as hunting, fishing, collecting ice water, and berry picking also promote physical activity, which was another important HFN intervention program component. Promotion of healthy foods and de-promotion of unhealthy foods was undertaken in grocery stores, at community sites, through posters, flyers, interactive sessions, educational displays, and through media such as radio and television announcements [13]. For example, materials were developed to promote consumption of water in place of carbonated beverages and posters displayed nutrient content comparisons between traditional meat such as Arctic char and caribou versus processed meat in grocery stores [28]. Program implementation strategies included healthy breakfasts, healthy meal planning and cooking, and education sessions on consuming sufficient amounts of vitamins and minerals, among other activities to promote healthy diet. Implementation sites included food stores, health clinics, offices, as well as at community special events, such as feasts [23]. Similar interventions were displayed through local television ads, and local radio broadcast stories featuring family activities to improve diet and exercise [32].

\section{Data collection}

Data collection was carried out at two time points in each community: baseline and 12 months post-intervention. Baseline data were collected between June and October 2008 (summer to fall) for the NU communities and between July 2007 and July 2008 for the NWT communities [13]. Hence, the one-year intervention period commenced October 2008 and July 2008 for the NU and NWT communities, respectively [28]. Pre- and post-intervention data were collected by local community health workers, community members, and university students all of whom were trained by the principal investigator (S.S.) in questionnaire administration and anthropometry to ensure standardization. Anthropometric measurements (height and weight) were obtained in duplicate and recorded [13]. Culturally appropriate quantitative food frequency questionnaires (QFFQ) were used to assess dietary intake at both time points. These QFFQs were previously developed and validated specifically for Inuit and Inuvialuit populations and were designed to assess dietary intake in the respective communities [33,34]. Participants were asked to report frequency of consumption over a 30-day period choosing from eight categories which ranged from "never" to "two or more times per day." Participants reported average portion size using food models to increase participants' accuracy of quantification.

The Adult Impact Questionnaires (AIQ) determined food acquisition and preparation behaviors, as well as demographic, socioeconomic, and psychosocial factors. Community stakeholders assessed the AIQ using face validity and Cronbach's $\alpha$ indicated high internal reliability. Participants were asked for the first and second most commonly used preparation methods in the past 30 days. The questionnaire has been described previously [19]. Data collectors interviewed participants in their homes and the majority of interviews were conducted in English. Participants whose primary language was not English were interviewed by an interviewer fluent in the local language or by an interviewer aided by an interpreter. Institutional Review Board approval was obtained from the Committee on Research Ethics at the Cancer Research Centre in Hawaii and the University of North Carolina at Chapel Hill. The NU Research Institute, the Ethics Committee of the Beaufort Delta Health and Social Services Authority and the Aurora Research Institute in the NWT all provided research licenses. Informed written consent was obtained from all study participants. Participants were reimbursed for their time with CAD \$25 gift cards for use at local stores.

\section{Outcome measures}

The evaluation examined two primary outcome measures: i) consumption of de-promoted foods and ii) changes in food preparation methods. De-promoted food groups (i.e., for which consumption was discouraged) are described in Table 1 and included: high-fat meats; high-fat dairy; refined grains; high sugar drinks; unhealthy snacks; and unhealthy additions (such as high fat powdered creamer added to coffee).

The number of times a participant reported using a given preparation method most-often or second-mostoften to prepare food (in the past 30 days) were summed for pre- and post-intervention scores to assess the intervention impact on food preparation methods. Preparation methods that reduced or did not change the fat content of prepared foods were classified as healthy. These methods included: pan fried in own fat or water; pan fried in own fat or water and drained; pan fried in own fat, drained, and rinsed; cooked with cooking spray only; microwaved, baked, roasted, or broiled without added fat; grilled; boiled; cooked with a slow cooker; boiled and drained or skimmed; steamed; smoked; raw (or frozen raw); and dried. Preparation methods that increased fat content and were classified as unhealthy included: deep-fried in oil, lard, animal fat, or shortening; pan fried in oil, lard, animal fat, or shortening; and microwaved, baked, roasted, or broiled with added fat. 
Table 1 De-promoted food groups

\begin{tabular}{ll}
\hline Category & Food items \\
\hline High-fat meats & $\begin{array}{l}\text { Beef hamburger, chicken nuggets, fried chicken, lunch meat including klik and corned } \\
\text { beef, pepperoni sticks, fish battered and fried, hot dogs, and sausage or wieners. } \\
\text { High-fat dairy }\end{array}$ \\
$\begin{array}{l}\text { Whole milk, carnation, cream, and half and half. } \\
\text { Refined grains }\end{array}$ & Fried bannock, white bread, sweet cereals including frosted flakes, and honey nut cheerios. \\
Unhealthy drinks & Regular pop, sweetened juice, sweetened drink including Tang, fruit punch, and kool-aid. \\
Unhealthy snacks & All chips, cheese curls, and regular popcorn ${ }^{\dagger}$. \\
Unhealthy additions & Regular coffeemate, sugar or honey, regular salad dressing ${ }^{\dagger},{\text { regular butter, margarine, lard, and mayo }{ }^{\dagger} .}^{*}$
\end{tabular}

*Nunavut.

${ }^{\dagger}$ Northwest Territories.

\section{Data analysis}

Baseline differences in demographic and socioeconomic variables between communities by intervention assignment were analyzed using the Student's $t$-test for continuous normally distributed variable and the $x^{2}$ test for categorical variables.

The NU and NWT data were combined and individual food intake data were placed into their respective food group categories. To compare control and intervention communities' pre- and post-intervention dietary behavior, the mean and standard deviation (SD) of total intake (gram/day), portion weight (gram/day), and frequency of intake (times/day) of de-promoted food groups were calculated for each control and intervention group independently at both time points. Dietary outcome measures included pre- and post-intervention changes to intake of each food group (total intake, portion weight, frequency of intake) and were determined using the following formula: $\Delta$ Change $=[$ mean (post pre in intervention group)] - [mean (post - pre in control group)]. A positive change indicated a larger pre- to post-intervention change in intervention communities than in control communities. Since the pre- to postintervention changes in food group intake were normally distributed, a Student's $t$-test was used to compare the intervention and control communities. Significance of pre- to post-intervention changes within a given community for each intervention and control communities were determined using a paired t-test for normally distributed variables or a Wilcoxon Signed Rank Sum Test for non-normally distributed variables. The impact of the intervention was assessed using analysis of covariance (ANCOVA) as the suggested method for comparing before and after experimental studies [35]. For these analyses we adjusted for the age, sex, BMI, smoking, education, MSL life score, percent of people living in households with income support, and percent of the family member employed. Data were analyzed using SAS statistical software, version 9.3 (SAS Institute, Inc., Cary, NC). All tests and p-values were two-sided and considered statistically significant at $\alpha \leq 0.05$.

\section{Results}

A total of 441 QFFQs and 494 AIQs were collected at baseline; response rates ranged from $74-93 \%$ in NU and from $65-85 \%$ in the NWT communities. Only participants who completed both pre- and post-intervention QFFQs $(\mathrm{n}=332)$, and pre- and post-intervention AIQs $(\mathrm{n}=378)$ were included in the analyses. Table 2 describes the 15 most commonly used preparation methods for eight foods: bannock, chicken, pork or beef, Arctic char (fish), seal, muskox or caribou, potatoes, and eggs.

Now I am going to ask you about how your household usually prepares different foods.

- Please think about how the foods listed here were cooked at home IN THE PAST 30 DAYS.

- How did you most often cook [food name] (Method \#1) in the past 30 days?

- Now tell me how you next most often cooked [food name] (Method \#2).

- Please refer to Part 3 on the answer sheet for response choices.

Table 3 describes the demographic characteristics of Inuit/Inuvialuit men and women by intervention assignment. Compared to the control communities $(n=111)$, participants in the intervention communities $(n=221)$ were significantly older $(p=0.01)$ and were less likely to have at least one household member on income support $(p=0.03)$, but were similar in all other demographic variables.

Changes in frequency (times/day), total intake (g/day) and portion sizes (g/day) of food intake between and within intervention and control groups are presented in Table 4. The frequency of high-fat meat consumption significantly decreased in the intervention communities $(\Delta=-0.2$ times/ day) and remained constant in the control communities. There was a significant decrease in the frequency of highfat dairy product consumption in the intervention communities from 0.2 to 0.1 times/day $(\Delta=-0.1$ times/day); in contrast, the frequency of high-fat dairy product consumption in the control communities increased from 0.1 to 0.2 times/day. The control communities had a significant 
Table 2 Adult Impact Questionnaire (AIQ) (Food preparation methods section)

\begin{tabular}{|c|c|c|c|}
\hline & \multicolumn{2}{|c|}{ Cooking method } & \\
\hline & $\# 1$ & $\# 2$ & \\
\hline Food & First most used methods & Second most used method & Cooking method options \\
\hline Bannock & & & $1=$ Did not cook in last 30 days \\
\hline Chicken & & & $2=$ Deep-fried in oil, lard, animal fat, or shortening \\
\hline Pork or beef & & & $3=$ Pan fried in oil, lard, animal fat, or shortening \\
\hline Fish (Arctic char) & & & $4=$ Pan fried in own fat or water \\
\hline Seal & & & $5=$ Pan fried in own fat or water and drained \\
\hline Muskox or caribou & & & $6=$ Pan fried in own fat, drained, and rinsed \\
\hline Potatoes & & & $7=$ Cooked with cooking spray only \\
\hline Eggs & & & $8=$ Microwaved, baked, roasted, broiled without added fat \\
\hline & & & $9=$ Microwaved, baked, roasted, broiled with added fat \\
\hline & & & $10=$ Grilled \\
\hline & & & 11 = Boiled, cooked with a slow cooker \\
\hline & & & $12=$ Boiled and drained or skimmed \\
\hline & & & $13=$ Steamed \\
\hline & & & $14=$ Smoked \\
\hline & & & $15=$ Raw (or frozen raw) \\
\hline & & & $16=$ Dried \\
\hline & & & $17=$ Other \\
\hline & & & $18=$ No other method \\
\hline
\end{tabular}

increase in the frequency of refined grain product consumption (0.9 to 1.2 times/day) and unhealthy drinks (1.3 to 1.6 times/day). Within both treatment groups there was a significant increase in frequency of unhealthy additions intakes; however, the change was not statistically significant between intervention and control groups.

Total intake of high-fat meat significantly decreased in the intervention group from 46 to $27 \mathrm{~g} /$ day and increased in the control group from 24 to $33 \mathrm{~g} /$ day $(\Delta=-27.9 \mathrm{~g} /$ day $)$ but this was not significant statistically. Compared to the control group the portion size of high-fat meat intake decreased significantly in the intervention group $(\Delta=-73.0 \mathrm{~g} /$ day $)$. The decrease in high-fat meats can, in part, be attributed to the significant change in processed beef or pork total intake within intervention groups (-16.8 g/day, data not shown). There was a nonsignificant decrease (19 to $11 \mathrm{~g} /$ day) in total intake of high-fat dairy products in the intervention communities, while intake significantly increased in the control communities from 6 to $18 \mathrm{~g} /$ day $(\Delta=-19.8 \mathrm{~g} /$ day). Unhealthy drinks significantly decreased within the intervention group from 754 to $587 \mathrm{~g} /$ day. Unhealthy snacks and additions significantly decreased within both the intervention and control groups, however there was no significant difference between the intervention and control groups (Table 4).
In fully adjusted ANCOVA analysis, receiving the intervention was significantly inversely associated with daily de-promoted grain intake $(\beta=-26,95 \% \mathrm{CI}:-46,-6)$. A male gender was associated with a higher intake of highfat meats $(\beta=20,95 \% \mathrm{CI}: 7,33)$ and de-promoted grains $(\beta=42,95 \%$ CI: 17,67$)$. Participants with the highest MSL score compared with the reference group had a lower depromoted grain intake ( $\beta=-30,95 \% \mathrm{CI}:-57,-3)$. Every 10 year increase in age was associated to 112 grams of less de-promoted drink consumption (95\% CI: -186, -39). People living in households with income support and/or family member employed had a lower intake of depromoted additions than people without supports $(\beta=-14$, 95\% CI: $-24,-5)$.

Table 5 shows pre- to post-intervention changes for the most commonly used healthy and unhealthy food preparation methods between and within intervention assignment groups.

Healthy preparation methods increased significantly in the intervention group from 3.9 to 4.3 times/day, and there was a significant pre- to post-intervention change between groups $(\Delta=0.5$ times/day). Unhealthy preparation methods decreased within the intervention group from 2.0 to 1.6 times/day $(\mathrm{p} \leq 0.0001)$. Pre- to postintervention changes between the intervention and control groups included: microwaved, baked, roasted, broiled with no added fat $(\Delta=0.5$ times/day, $\mathrm{p} \leq 0.05)$; pan fried in 
Table 3 Characteristics of the study sample by intervention assignment

\begin{tabular}{|c|c|c|c|c|c|}
\hline & \multicolumn{2}{|c|}{$\begin{array}{l}\text { Intervention } \\
(\mathrm{n}=221)\end{array}$} & \multicolumn{2}{|c|}{$\begin{array}{l}\text { Control } \\
(n=111)\end{array}$} & \multirow[t]{2}{*}{$\mathrm{p}$-value } \\
\hline & Mean & SD & Mean & SD & \\
\hline \multirow[t]{2}{*}{ Age (years) } & 45.5 & 14.1 & 41.9 & 10.7 & $0.01^{1}$ \\
\hline & $\mathbf{N}$ & $\%$ & n & $\%$ & \\
\hline \multicolumn{6}{|l|}{ Gender } \\
\hline Men & 44 & 20 & 20 & 18 & \\
\hline Women & 177 & 80 & 91 & 82 & $0.68^{2}$ \\
\hline \multicolumn{6}{|l|}{ Material Style of Life (MSL) } \\
\hline Low (MSL score <8) & 64 & 30 & 28 & 25 & \\
\hline Intermediate (MSL score 8-12) & 77 & 36 & 35 & 32 & \\
\hline High (MSL score >12) & 73 & 34 & 47 & 43 & $0.31^{2}$ \\
\hline \multicolumn{6}{|l|}{ Education $^{3}$} \\
\hline Low & 81 & 38 & 46 & 42 & \\
\hline Intermediate & 87 & 41 & 39 & 36 & \\
\hline High & 45 & 21 & 24 & 22 & $0.66^{2}$ \\
\hline \multicolumn{6}{|c|}{$\begin{array}{l}\text { Number of adults living in the household } \\
\text { who receive income support }\end{array}$} \\
\hline No & 56 & 26 & 24 & 22 & \\
\hline Yes & 159 & 74 & 85 & 78 & $0.03^{2}$ \\
\hline \multicolumn{6}{|l|}{ People in household working } \\
\hline No & 130 & 60 & 52 & 48 & \\
\hline Yes & 85 & 40 & 57 & 52 & $0.43^{2}$ \\
\hline
\end{tabular}

own fat or water and drained (and/or rinsed) $(\Delta=0.2, \mathrm{p} \leq$ $0.05)$; microwaved, baked, roasted, broiled with added fat $(\Delta=-0.7$ times/day, $\mathrm{p} \leq 0.0001)$; and pan fried in oil, lard, animal fat, or shortening $(\Delta=-0.1$ times/day, $\mathrm{p} \leq 0.05)$. The intervention group had a significant decrease in food preparation through deep frying in oil, lard, animal fat or shortening, but the control group had a greater decrease in this preparation method $(\Delta=0.5, \mathrm{p} \leq 0.0001)$.

\section{Discussion}

Nutrition intervention programs may be beneficial for Inuit and Inuvialuit populations, which have an estimated threefold higher prevalence of heart disease compared to the Canadian national average $[19,36]$ and increased risk factors for diabetes, obesity, and hypertension [37]. It is well established that decreasing animal fats, including high-fat dairy products and partially hydrogenated fats, aids in the reduction and prevention of obesity and its related comorbidities [38,39]. Evidence also strongly supports an inverse relationship between the consumption of fruit and vegetables and risk of several cancers, heart disease, and overall mortality [40]. This may be due to the naturally occurring essential nutrients (e.g. antioxidants, fiber, and folic acid) within fruit and vegetables [38,41] Thus, the year-long pilot HFN intervention was designed in part to reduce reliance on high fat, high sugar, nonnutrient-dense foods and beverages and unhealthy preparation methods that added fat, and to increase utilization of healthier cooking methods, in an attempt to reduce chronic disease risk. The results of the intervention were successful in reducing the consumption of de-promoted foods and in the utilization of unhealthy cooking. There was a significant increase in the use of healthy preparation methods within 12 months. The pre-intervention evaluation of this population indicated that pan-frying with fat was one of the most frequently reported methods of preparation $[18,19]$. Post-intervention results from the intervention communities indicated a decrease in the use of this method and a concurrent increase in the use of panfrying methods that did not add fat, thereby reducing added fat consumption in the population under intervention. Several epidemiological studies suggest that the consumption of fried, boiled or roasted red meat is associated with the development of cancer; it has been proposed that heterocyclic aromatic amines, potent mutagens present at $\mathrm{ng} / \mathrm{kg}$ levels in cooked foods play an important role in the 
Table 4 Change in frequency, total intake and portion size of consumption of de-promoted food groups by intervention assignment among adult Inuit and Inuvialuit

\begin{tabular}{|c|c|c|c|c|c|c|c|c|c|c|c|c|c|}
\hline \multirow{3}{*}{$\begin{array}{l}\text { De-promoted } \\
\text { food groups }\end{array}$} & \multicolumn{6}{|c|}{ Intervention } & \multicolumn{6}{|c|}{ Control } & \multirow{3}{*}{$\begin{array}{l}\Delta \text { intervention } \\
\text { vs. } \Delta \text { control }^{2}\end{array}$} \\
\hline & \multicolumn{2}{|c|}{ Pre $(n=221)$} & \multicolumn{2}{|c|}{ Post $(n=221)$} & \multicolumn{2}{|c|}{$\Delta^{1}$} & \multicolumn{2}{|c|}{ Pre $(n=111)$} & \multicolumn{2}{|c|}{ Post $(n=111)$} & \multicolumn{2}{|c|}{$\Delta^{1}$} & \\
\hline & Mean & SD & Mean & SD & Mean & SD & Mean & SD & Mean & SD & Mean & SD & \\
\hline \multicolumn{14}{|l|}{ Frequency (time/day) } \\
\hline High-fat meats & 0.4 & 0.5 & 0.3 & 0.3 & $-0.2^{\dagger}$ & 0.4 & 0.3 & 0.3 & 0.3 & 0.4 & 0.0 & 0.4 & $-0.2^{\dagger}$ \\
\hline High-fat dairy products & 0.2 & 0.4 & 0.1 & 0.4 & $-0.1^{*}$ & 0.5 & 0.1 & 0.3 & 0.2 & 0.4 & $0.1^{*}$ & 0.5 & $-0.2^{\ddagger}$ \\
\hline Refined grain products & 0.8 & 0.7 & 0.9 & 0.8 & 0.0 & 0.8 & 0.9 & 0.6 & 1.2 & 1.0 & $0.3^{\dagger}$ & 1.0 & $-0.3^{*}$ \\
\hline Unhealthy drinks & 1.3 & 1.0 & 1.3 & 1.1 & 0.0 & 1.1 & 1.3 & 1.1 & 1.6 & 1.1 & $0.3^{*}$ & 1.2 & $-0.3^{*}$ \\
\hline Unhealthy snacks & 0.3 & 0.5 & 0.3 & 0.4 & 0.0 & 0.4 & 0.3 & 0.4 & 0.3 & 0.3 & 0.0 & 0.4 & -0.0 \\
\hline Unhealthy additions & 2.0 & 1.5 & 2.3 & 1.5 & $0.3^{*}$ & 1.4 & 2.0 & 1.4 & 2.4 & 1.5 & $0.4^{\ddagger}$ & 1.4 & -0.1 \\
\hline \multicolumn{14}{|l|}{ Total Intake (g/day) } \\
\hline High-fat meats & 46 & 72 & 27 & 47 & $-19.0^{\dagger}$ & 66.8 & 24 & 24 & 33 & 73 & 8.9 & 69.6 & $-27.9^{\ddagger}$ \\
\hline High-fat dairy products & 19 & 88 & 11 & 41 & -8.0 & 91.3 & 6 & 17 & 18 & 52 & $11.8^{*}$ & 50.7 & $-19.8^{*}$ \\
\hline Refined grain products & 69 & 67 & 69 & 77 & 0.7 & 85.9 & 110 & 127 & 112 & 132 & 2.3 & 150.5 & -1.6 \\
\hline Unhealthy drinks & 754 & 885 & 587 & 846 & $-166.6^{*}$ & 808.2 & 727 & 785 & 749 & 966 & 21.9 & 1028.3 & -188.5 \\
\hline Unhealthy snacks ${ }^{3}$ & 49 & 156 & 17 & 24 & $-31.5^{*}$ & 153.9 & 36 & 70 & 17 & 21 & $-18.6^{*}$ & 68.8 & $-12.9^{3}$ \\
\hline Unhealthy additions & 48 & 52 & 37 & 40 & $-11.1^{\ddagger}$ & 47.3 & 45 & 55 & 33 & 46 & $-12.1^{*}$ & 53.8 & 0.9 \\
\hline \multicolumn{14}{|l|}{ Portion size (g/day) } \\
\hline High-fat meats & $281^{\dagger}$ & 199 & $195^{\dagger}$ & 161 & -85.6 & 196.8 & 232 & 168 & 219 & 244 & -12.6 & 244.0 & $-73.0^{*}$ \\
\hline High-fat dairy products & 35 & 131 & 26 & 76 & -8.3 & 142.6 & 28 & 81 & 42 & 92 & 14 & 114.0 & -22.3 \\
\hline Refined grain products & $204^{*}$ & 136 & $178 *$ & 110 & -26.6 & 155.9 & $274 \neq$ & 186 & $216 \neq$ & 116 & -57.6 & 181.7 & 31.0 \\
\hline Unhealthy drinks & $944^{\dagger}$ & 829 & $723^{\dagger}$ & 615 & -221.2 & 703.7 & $946^{*}$ & 639 & $778^{*}$ & 511 & -168.4 & 625.9 & -52.8 \\
\hline Unhealthy snacks ${ }^{3}$ & $106^{\dagger}$ & 129 & $58^{+}$ & 41 & -48.3 & 127.7 & $138^{\dagger}$ & 109 & $65^{\dagger}$ & 36 & -73.8 & 116.6 & 25.5 \\
\hline Unhealthy additions & $56^{\dagger}$ & 52 & $42^{\dagger}$ & 48 & -13.9 & 49.7 & $56^{*}$ & 59 & $40^{*}$ & 50 & -16.3 & 54.3 & 2.4 \\
\hline
\end{tabular}

${ }^{1} \Delta$ Change between post and pre intervention in intervention or control group $=$ [mean (post - pre)].

${ }^{2} \Delta$ Change intervention vs. $\Delta$ control $=$ [mean (post - pre in intervention group)] - [mean (post - pre in control group)].

${ }^{3} \mathrm{~A}$ Wilcoxon Signed Rank Sum Test was performed.

A t- test was performed on all other $p$-values.

${ }^{*} \mathrm{p} \leq 0.05 ; \neq \mathrm{p} \leq 0.001 ;{ }^{\dagger} \mathrm{p} \leq 0.0001$.

aetiology of human cancer [42,43]. Therefore, avoiding high-temperature cooking methods may lower the risk of cancer.

Compared to the control group, the intervention group had a greater reduction in intake of de-promoted high-fat meats, high-fat dairy, refined grain products, and unhealthy drinks, all of which are commonly consumed food groups in this population $[11,12,27,29]$. Baseline studies determined that sweetened juices/drinks made the largest contribution to energy, carbohydrate, and sugar in NU and the first and second largest contribution in the NWT. Regular soft drinks and white bread were also top contributors to energy, carbohydrate, and sugar for both populations. Furthermore, butter, margarine, lard, and high-fat meats, including sausages and lunchmeats, were the top contributors to fat $[16,17,27,29]$. The reduced consumption of de-promoted food groups (particularly refined grains, unhealthy drinks, high-fat dairy products and highfat meats) in the intervention group compared to control could explain the decreases in energy intake (average of $317 \mathrm{kcal} /$ day), protein intake ( $21 \mathrm{~g} /$ day), carbohydrate intake $(37 \mathrm{~g} /$ day), and overall Body Mass Index (BMI) ( $\mathrm{p}=$ 0.002) [44]. Improved intake of vitamin A and D were also observed. These nutrients are naturally abundant in the traditional foods consumed by Arctic Indigenous populations $[10,13,45]$. Therefore, it may be inferred that dietary adequacy improved, in part, as a result of the observed significant increase in traditional food intake (from 1.4 to 1.7 times/day within the intervention group).

To our knowledge, there have been no studies on the impact of interventions within Inuit/Inuvialuit populations; therefore, the effectiveness of HFN's community-based program must be compared with interventions targeting other Indigenous and/or remote populations. A recent review on the community-based interventions in prepared-food sources found some promising results however the outcome measures were limited [46]. Many of the interventions included in this review were not formal studies but 
Table 5 Change in the most frequently reported preparation methods pre- and post- intervention by intervention assignment among adult Inuit and Inuvialuit

\begin{tabular}{|c|c|c|c|c|c|c|c|c|c|}
\hline \multirow[t]{3}{*}{ Preparation methods } & \multicolumn{4}{|c|}{ Intervention } & \multicolumn{4}{|c|}{ Control } & \multirow{3}{*}{$\begin{array}{l}\Delta \text { intervention } \\
\text { vs. } \Delta \text { control }{ }^{1}\end{array}$} \\
\hline & \multicolumn{2}{|c|}{ Pre $(n=246)$} & \multicolumn{2}{|c|}{ Post $(n=246)$} & \multicolumn{2}{|c|}{ Pre $(n=132)$} & \multicolumn{2}{|c|}{ Post $(n=132)$} & \\
\hline & Mean & SD & Mean & SD & Mean & SD & Mean & SD & \\
\hline Unhealthy methods $^{2}$ & $2.0^{\dagger}$ & 1.0 & $1.6^{\dagger}$ & 0.9 & 1.9 & 1.1 & 1.8 & 1.0 & -0.2 \\
\hline Healthy methods ${ }^{3}$ & $3.9 \neq$ & 1.3 & $4.3 \neq$ & 1.3 & 4.5 & 1.5 & 4.3 & 1.4 & $0.5 \neq$ \\
\hline \multicolumn{10}{|l|}{ Select preparation methods } \\
\hline Microwaved, baked, roasted, broiled (no added fat) ${ }^{2}$ & $2.0^{*}$ & 1.6 & $2.2^{*}$ & 1.4 & 2.3 & 1.6 & 2.0 & 1.3 & $0.5^{*}$ \\
\hline Microwaved, baked, roasted, broiled (added fat) ${ }^{2}$ & $0.7^{*}$ & 1.4 & $0.4^{*}$ & 0.7 & $0.1^{\dagger}$ & 0.4 & $0.4^{\dagger}$ & 0.7 & $-0.7^{\dagger}$ \\
\hline Deep fried in oil, lard, animal fat, or shortening ${ }^{2}$ & $0.3^{\dagger}$ & 0.7 & $0.1^{\dagger}$ & 0.3 & $0.9^{\dagger}$ & 1.4 & $0.2^{+}$ & 0.4 & $0.5^{\dagger}$ \\
\hline Pan fried in oil, lard, animal fat, or shortening ${ }^{2}$ & $2.6 \neq$ & 1.7 & $2.1 \neq$ & 0.3 & $2.6^{*}$ & 1.8 & $2.2^{*}$ & 1.4 & $-0.1^{*}$ \\
\hline Pan fried in own fat or water and drained; rinsed ${ }^{4}$ & $0.1^{*}$ & 0.3 & $0.2^{*}$ & 0.5 & 0.2 & 0.6 & 0.2 & 0.5 & $0.2^{*}$ \\
\hline Raw (or frozen raw), dried ${ }^{4}$ & $0.7^{*}$ & 0.9 & $0.8^{*}$ & 0.9 & 0.8 & 1.0 & 0.7 & 0.8 & 0.2 \\
\hline
\end{tabular}

${ }^{1}$ Change in number of times method reported by individuals $=$ (post - pre-intervention) - (post - pre-control).

${ }^{2}$ Wilcoxon Signed Rank Sum Test to test the intra-group difference between pre- and post- intervention.

${ }^{3}$ Paired t-test to test the intra-group difference between pre- and post- intervention.

${ }^{4}$ Two-sample t-test with equal variances.

${ }^{*} \mathrm{p} \leq 0.05 ; \neq \mathrm{p} \leq 0.001 ;{ }^{\dagger} \mathrm{p} \leq 0.0001$.

rather certification or campaign programs operated by local health departments. Therefore, the voluntary nature of the programs may explain why they varied in levels of reach. Similar to the present study, a store-based intervention targeting Native American adults living on Arizona reservations saw no change in the consumption of high-sugar, high-fat snacks and fast food. They found that the consumption of the comparison group increased significantly for less healthy foods over the year of the intervention program, which may indicate that in general, people are eating less healthy. It is possible that the program helped keep the intervention group's diets from getting unhealthier [47].

A family-based intervention conducted with the Six Nations Reserve in Ohsweken, Ontario made similar observations [48]. They reported a decrease in intake of fatty foods, oils, and sodas paralleling HFN's decrease in highfat meat consumption, unhealthy drinks, and unhealthy cooking methods. However, some interventions among Indigenous populations outside of North America have shown promising results. Promotion of local foods and a traditional diet have resulted in increased intake of local accessible foods as well as increased nutrient intake in Indigenous populations in Micronesia [45], the Dalit in India [49], and Australia [50].

HFN was a community-based and community-driven intervention project. Community interventions have much greater potential to reduce weight and related health risks than individual weight loss programs [48,51]. There is greater possibility for sustainability if the programs partner with community-based institutions such as schools and stores [52]. However, it is important to consider the remoteness of these Arctic populations and the economic and environmental barriers that limit the feasibility of an active lifestyle and access to fresh nutritious foods. Future program development should focus on mitigating these barriers by improving the accessibility and affordability of healthy foods (e.g. fruit and vegetables and low-fat, lowsugar store bought items); furthermore, traditional foods high in protein, iron, and vitamins should be promoted $[10,16,17,53]$. Marine omega- 3 fatty acids, contained in Arctic char and other fish and marine mammals, have proven protective effects against coronary heart disease in several diverse populations [54]. Continued efforts to revitalize traditional food systems, such as hunting, gathering, and food-sharing, are equally important as they have a multitude of health and well-being benefits. Ongoing trials with longer intervention periods and larger sample populations are needed to monitor HFN's impact on chronic disease risk.

\section{Strengths and limitations}

The sample was predominantly female (80-82\%) because the study targeted the primary food shoppers and preparers. Bias may also have been introduced by the lower response rates that were observed for some communities. Given the potential for variation in access to store bought and traditional foods throughout the year, differences in the time of year for collection of baseline and follow up data, particularly for the NWT communities, may also have led to bias. In addition, limited data were available for potential confounders. However, baseline dietary differences between control and intervention groups were unchanged when stratified analyses were examined for age and income support (variables that were differentially distributed among the control and intervention groups). It is unlikely that the control groups were exposed to the 
intervention content that was disseminated via television and radio, as access to media between communities is limited in this remote region. Therefore, results may not be generalizable to male Inuit and Inuvialuit populations. Recall bias, which may occur with QFFQs, is another potential limitation [55]. However, validation studies of the QFFQs used in this study confirmed relative agreement with multiple 24-hour recalls in this population [33,34].

This study provides the first data on the impact of a multi-institutional, community-based nutrition intervention program among Inuit in NU and Inuvialuit in the NWT. These data will contribute not only to the limited literature, but may also contribute to government policy decision-making related to Inuit and Inuvialuit nutrition and health. The data collection instruments are current and culturally relevant for this population.

\section{Conclusion}

The results from this study demonstrate that the HFN program was effective for reducing consumption of high fat, high sugar foods and beverages of low nutritional density and reliance on preparation methods that add fat to foods. These findings may be considered for other interventions with Indigenous populations living in other remote areas worldwide.

\author{
Abbreviations \\ NU: Nunavut; NWT: Northwest Territories; HFN: Healthy Foods North; \\ QFFQ: Quantitative food frequency questionnaire; AIQ: Adult Impact \\ Questionnaire; MSL: Material Style of Life; IEAS: Intervention Exposure \\ Assessment Survey.
}

\section{Competing interests}

The authors declare they have no competing interests.

\section{Authors' contributions}

FK conducted the data analysis, drafted and finalized the manuscript. MP drafted the manuscript. EM and LB initiated and implemented the intervention in NWT and Nunavut and oversaw all field activities. AC critically reviewed the manuscript. SS developed the designed the study, trained data collectors, and oversaw data collection. All authors were responsible for interpretation of the data and critically reviewed its content and have approved the final version submitted for publication.

\section{Acknowledgments}

We would like to thank all participants in the communities where the research was conducted. We also would like to thank the communities, the NorthWest Company, Arctic Co-operatives Limited, Stanton's, and local store managers and shops for their support and participation. We would especially like to express our gratitude to all of the individuals whose help, generosity, and dedication has made this research possible; Dr. Andrew Applejohn, the Aurora Research Institute, Ms. Audra Donnison, Ms. Annie Buchan, Ms. Rahabi Kamookak, Ms. Julia Ogina, Ms. Nora Niptanatiak, Ms. Rhonda Reid, Mr. James Howard, Ms. Sarah Reaburn, Ms. Anita Pokiak, Ms. Melanie Keevik, Ms. Shelley Wolki, Ms. Bessie Hagan, and Ms. Sandra Hanson. The project was supported by American Diabetes Association Clinical Research award 1-08-CR-57, Government of Nunavut Department of Health and Social Services, Government of Northwest Territories Department of Health and Social Services, Health Canada, Public Health Agency of Canada, and the Nunavut and Northwest Territories Public Health Association.

\section{Author details}

Aboriginal and Global Health Research Group, Department of Medicine, Faculty of Medicine and Dentistry, University of Alberta, Unit 5-10, University Terrace, 8303-112 Street, Edmonton, AB T6G 2T4, Canada. ²Department of Health, Behavior and Society, Bloomberg School of Public Health, Johns Hopkins University, Baltimore, MD, USA. ${ }^{3}$ Office of the Chief Public Health Officer, Department of Health and Social Services, Government of the Northwest Territories, 6th Floor, Centre Square Tower, Box 1320, Yellowknife, NT X1A 2L9, Canada.

\section{Received: 24 September 2013 Accepted: 24 June 2014}

Published: 4 July 2014

\section{References}

1. Inuit Tapiriit Kanatami: Inuit statistical profile. https:/www.itk.ca/system/files force/InuitStatisticalProfile2008_0.pdf. 2008. 4-2-2009. Ref Type: Electronic Citation.

2. Statistics Canada: Health Trends. Statistics Canada Catalogue; 2014. 12-6-2014. Ref Type: Report.

3. Inuit Tapiriit Kanatami: Inuit \& Cancer: Fact Sheets. 2009, Ref Type: Report

4. Frohlich $\mathrm{KL}$, Ross N, Richmond C: Health disparities in Canada today: some evidence and a theoretical framework. Health Policy 2006, 79:132-143.

5. Institute of Health Economics: IHE In Your Pocket 2010: A Handbook of Health Economic Statistics. Alberta, Canada; 2010. Ref Type: Report.

6. Raine KD: Addressing poor nutrition to promote heart health: moving upstream. Can J Cardiol 2010, 26(Suppl C):21C-24C.

7. Uauy R, Kain J, Mericq V, Rojas J, Corvalan C: Nutrition, child growth, and chronic disease prevention. Ann Med 2008, 40:11-20.

8. Popkin BM: Global nutrition dynamics: the world is shifting rapidly toward a diet linked with noncommunicable diseases. Am J Clin Nutr 2006, 84:289-298.

9. Bjerregaard P, Young TK, Dewailly E, Ebbesson SO: Indigenous health in the Arctic: an overview of the circumpolar Inuit population. Scand J Public Health 2004, 32:390-395.

10. Kuhnlein HV, Receveur O, Soueida R, Egeland GM: Arctic indigenous peoples experience the nutrition transition with changing dietary patterns and obesity. J Nutr 2004, 134:1447-1453.

11. Erber E, Beck L, Hopping BN, Sheehy T, De Roose E, Sharma S: Food patterns and socioeconomic indicators of food consumption amongst Inuvialuit in the Canadian Arctic. J Hum Nutr Diet 2010, 23:59-66.

12. Hopping BN, Erber E, Mead E, Sheehy T, Roache C, Sharma S: Socioeconomic indicators and frequency of traditional food, junk food, and fruit and vegetable consumption amongst Inuit adults in the Canadian Arctic. J Hum Nutr Diet 2010, 23:51-58.

13. Sharma S: Assessing diet and lifestyle in the Canadian Arctic Inuit and Inuvialuit to inform a nutrition and physical activity intervention programme. J Hum Nutr Diet 2010, 23:5-17.

14. Damman S, Eide WB, Kuhnein HV: Indigenous peoples' nutrition transition in a right to food perspective. Food Policy 2008, 33:135-155.

15. Richmond CA, Ross NA: The determinants of First Nation and Inuit health: a critical population health approach. Health Place 2009, 15:403-411.

16. Erber E, Hopping BN, Beck L, Sheehy T, De Roose E, Sharma S: Assessment of dietary adequacy in a remote Inuvialuit population. $J$ Hum Nutr Diet 2010, 23:35-42.

17. Hopping BN, Mead E, Erber E, Sheehy C, Roache C, Sharma S: Dietary adequacy of Inuit in the Canadian Arctic. J Hum Nutr Diet 2010, 23:27-34

18. Mead E, Gittelsohn J, De Roose E, Sharma S: Important psychosocial factors to target in nutrition interventions to improve diet in Inuvialuit communities in the Canadian Arctic. J Hum Nutr Diet 2010, 23:92-99.

19. Mead E, Gittelsohn J, Roache C, Sharma S: Healthy food intentions and higher socioeconomic status are associated with healthier food choices in an Inuit population. J Hum Nutr Diet 2010, 23:83-91.

20. Burghardt JA, Devaney BL, Gordon AR: The School Nutrition Dietary Assessment Study: summary and discussion. Am J Clin Nutr 1995, 61:252S-257S

21. Snyder MP, Obarzanek E, Montgomery DH, Feldman H, Nicklas T, Raizman D, Rupp J, Bigelow C, Lakatos E: Reducing the fat content of ground beef in a school foodservice setting. J Am Diet Assoc 1994, 94:1135-1139.

22. Gittelsohn J, Wolever TM, Harris SB, Harris-Giraldo R, Hanley AJ, Zinman B: Specific patterns of food consumption and preparation are associated with diabetes and obesity in a Native Canadian community. J Nutr 1998, 128:541-547. 
23. Ho LS, Gittelsohn J, Rimal R, Treuth MS, Sharma S, Rosecrans A, Harris SB: An integrated multi-institutional diabetes prevention program improves knowledge and healthy food acquisition in northwestern Ontario First Nations. Health Educ Behav 2008, 35:561-573.

24. Gittelsohn J, Roache C, Kratzmann M, Reid R, Ogina J, Sharma S: Participatory research for chronic disease prevention in Inuit communities. Am J Health Behav 2010, 34:453-464.

25. Gittelsohn J, Song HJ, Suratkar S, Kumar MB, Henry EG, Sharma S, Mattingly M, Anliker JA: An urban food store intervention positively affects food-related psychosocial variables and food behaviors. Health Educ Behav 2010, 37:390-402

26. Gittelsohn J, Rowan M, Gadhoke P: Interventions in small food stores to change the food environment, improve diet, and reduce risk of chronic disease. Prev Chronic Dis 2012, 9:E59.

27. Sharma S, Cao X, Roache C, Buchan A, Reid R, Gittelsohn J: Assessing dietary intake in a population undergoing a rapid transition in diet and lifestyle: the Arctic Inuit in Nunavut, Canada. Br J Nutr 2010, 103:749-759.

28. Sharma S, Gittelsohn J, Rosol R, Beck L: Addressing the public health burden caused by the nutrition transition through the Healthy Foods North nutrition and lifestyle intervention programme. J Hum Nutr Diet 2010, 23:120-128.

29. Sharma S, De RE, Cao X, Pokiak A, Gittelsohn J, Corriveau A: Dietary intake in a population undergoing a rapid transition in diet and lifestyle: the Inuvialuit in the Northwest Territories of Arctic Canada. Can J Public Health 2009, 100:442-448.

30. Mead E, Gittelsohn J, Kratzmann M, Roache C, Sharma S: Impact of the changing food environment on dietary practices of an Inuit population in Arctic Canada. J Hum Nutr Diet 2010, 23:18-26.

31. Statistics Canada: Statistics Canada. Aboriginal population profile. http://www12.statcan.gc.ca/census-recensement/2006/dp-pd/prof/92-594/ index.cfm?Lang=E .2006.4-7-2010. 2006. Ref Type: Electronic Citation.

32. Mead EL, Gittelsohn J, Roach C, Corriveau A, Sharma S: A community-based, environmental chronic disease prevention intervention to improve healthy eating psychosocial factors and behaviors in Indigenous populations in the Canadian Arctic. Health Educ Behav 2012, 40:592-602.

33. Pakseresht M, Sharma S: Validation of a quantitative food frequency questionnaire for Inuit population in Nunavut, Canada. J Hum Nutr Diet 2010, 23(Suppl 1):67-74.

34. Pakseresht M, Sharma S: Validation of a culturally appropriate quantitative food frequency questionnaire for Inuvialuit population in the Northwest Territories, Canada. J Hum Nutr Diet 2010, 23(Suppl 1):75-82.

35. Vickers AJ, Altman DG: Statistics notes: Analysing controlled trials with baseline and follow up measurements. BMJ 2001, 323:1123-1124.

36. Heart and Stroke Foundation of Canada: The Changing Face of Heart Disease and Stroke in Canada, 2000. 1999, Ref Type: Online Source.

37. Deering KN, Lix LM, Bruce S, Young TK: Chronic diseases and risk factors in Canada's northern populations: longitudinal and geographic comparisons. Can J Public Health 2009, 100:14-17.

38. Willett WC: Diet and health: what should we eat? Science 1994, 264:532-537.

39. Kuller LH: Dietary fat and chronic diseases: epidemiologic overview. J Am Diet Assoc 1997, 97:S9-S15.

40. World Health Organization: Report of the World Health Organization Study Group. Diet, Nutrition and the Prevention of Chronic. 2008, 9-92009. Ref Type: Report.

41. Bazzano LA, He J, Ogden LG, Loria CM, Vupputuri S, Myers L, Whelton PK: Fruit and vegetable intake and risk of cardiovascular disease in US adults: the first National Health and Nutrition Examination Survey Epidemiologic Follow-up Study. Am J Clin Nutr 2002, 76:93-99.

42. Joshi AD, John EM, Koo J, Ingles SA, Stern MC: Fish intake, cooking practices, and risk of prostate cancer: results from a multi-ethnic case-control study. Cancer Causes Control 2012, 23:405-420.

43. Liao GZ, Wang GY, Xu XL, Zhou GH: Effect of cooking methods on the formation of heterocyclic aromatic amines in chicken and duck breast. Meat Sci 2010, 85:149-154.

44. Bains A, Pakseresht M, Roache C, Beck L, Sheehy T, Gittelsohn J, Corriveau A, Sharma S: Healthy Foods North improves diet among Inuit and Inuvialuit women of childbearing age in Arctic Canada. J Hum Nutr Diet 2013, 27:175-185.

45. Kaufer L, Englberger L, Cue R, Lorens A, Albert K, Pedrus P, Kuhnlein HV: Evaluation of a "traditional food for health" intervention in Pohnpei, Federated States of Micronesia. Pac Health Dialog 2010, 16:61-73.
46. Gittelsohn J, Lee-Kwan SH, Batorsky B: Community-based interventions in prepared-food sources: a systematic review. Prev Chronic Dis 2013, 10:E180.

47. Apache Healthy Stores: Apache Healthy Stores Community Workshop October 26-27. 2005, 3-19-2012. Ref Type: Online Source.

48. Anand SS, Davis AD, Ahmed R, Jacobs R, Xie C, Hill A, Sowden J, Atkinson S, Blimkie C, Brouwers M, Morrison K, de Koning L, Gerstein H, Yusuf S, SHARE-AP ACTION Investigators: A family-based intervention to promote healthy lifestyles in an aboriginal community in Canada. Can J Public Health 2007, 98:447-452.

49. Schmid MA, Salomeyesudas B, Satheesh P, Hanley J, Kuhnlein HV: Intervention with traditional food as a major source of energy, protein, iron, vitamin C and vitamin A for rural Dalit mothers and young children in Andhra Pradesh, South India. Asia Pac J Clin Nutr 2007, 16:84-93.

50. Lee AJ, Bonson AP, Yarmirr D, O'Dea K, Mathews JD: Sustainability of a successful health and nutrition program in a remote aboriginal community. Med J Aust 1995, 162:632-635.

51. Jeffery RW: Public health strategies for obesity treatment and prevention. Am J Health Behav 2001, 25:252-259.

52. Gittelsohn J, Dyckman W, Tan ML, Boggs MK, Frick KD, Alfred J, Winch PJ, Haberle H, Palafox NA: Development and implementation of a food store-based intervention to improve diet in the Republic of the Marshall Islands. Health Promot Pract 2006, 7:396-405.

53. Kuhnlein HV, Receveur O: Local cultural animal food contributes high levels of nutrients for Arctic Canadian Indigenous adults and children. J Nutr 2007, 137:1110-1114.

54. Hu FB, Willett WC: Optimal diets for prevention of coronary heart disease. JAMA 2002, 288:2569-2578.

55. Kristal AR, Peters U, Potter JD: Is it time to abandon the food frequency questionnaire? Cancer Epidemiol Biomarkers Prev 2005, 14:2826-2828.

doi:10.1186/1475-2891-13-68

Cite this article as: Kolahdooz et al:: Impact of the Healthy Foods North nutrition intervention program on Inuit and Inuvialuit food consumption and preparation methods in Canadian Arctic communities. Nutrition Journal 2014 13:68.

\section{Submit your next manuscript to BioMed Central and take full advantage of:}

- Convenient online submission

- Thorough peer review

- No space constraints or color figure charges

- Immediate publication on acceptance

- Inclusion in PubMed, CAS, Scopus and Google Scholar

- Research which is freely available for redistribution 